the volume under review, on an impressive scale, using the facilities of the Watson Scientific Computing Laboratory in New York and of the Institute for Numerical Analysis of the U.S. National Bureau of Standards at Los Angeles. From the functions $X$ and $Y$ so obtained, the Stokes parameters of the radiation emerging in different directions at the top and at the bottom of the atmosphere have been computed for different elevations of the Sun and different reflectivities of the ground. The results of these computations, performed by the authors at the Data Processing Centre of the University of California at Los Angeles, are then presented in this book.

The volume itself consists largely of an impressive set of tables, containing accurate data which should meet any conceivable problem encountered in the field of atmospheric optics for a long time to come, and represents a permanent contribution to the literature on physical meteorology. We can indeed agree with Chandrasekhar's words in the foreword to this book that ". . . with the publication of this volume, comprising the work of Dr. Sekera and his collaborators, the problem that was formulated by Rayleigh in 1871 has now at last found its complete solution".

ZDENĚK KOPAX

\section{STRUCTURE, LIFE-HISTORY AND DISTRIBUTION OF GNETUM}

\section{Gnetum}

By P. Maheshwari and Vimla Vasil. (Botanical Monograph No. 1.) Pp. xii +142 . (New Delhi Council of Scientific and Industrial Research, 1961.) Rs. 20.00; $40 s$.

GETUM is a genus consisting of rather more than thirty species of which most are woody climbers, but some are shrubs and small trees. It is confined to certain humid regions in South-east Asia, West Africa and the north-eastern parts of South America. It was at one time classified with Ephedra and Welwitschia in the order Gnetales; but it is now generally accepted that these last two genera are not very closely related to Gnetum, so that the order Gnetales is now thought of as consisting of this one genus. The chief botanical interest of the genus is that all its members exhibit, in their floral morphology, embryology and in the struature of their vegetative organs, a mixture of angiosperm and gymnosperm characters. In consequence the genus has been much discussed whenever the origin of the flowering plants is under consideration. To those botanists who are familiar with Gnetum mainly on account of its phylogenetic interest it may come as a surprise to learn that Gnetum gnemon is cultivated for the sake of its edible seeds, that fibre from the bark is used to make fishing nets and ropes, and the wood of old trees is used in cooperage.

The book under review is the first of a series of botanical monographs that is to be produced by the Indian Council of Scientific and Industrial Research. The senior author, who is professor of botany at Delhi, is already well known for the extensive programme of research carried on in collaboration with his pupils and associates, on the morphological aspects of the embryology of the flowering plants. His Embryology of Angiosperms is also much used as a work of reference and by students. In the monograph now under review the authors integrate and sum- marize all that has been done on the geographical distribution, morphology, anatomy and embryology of Gnetum. The relationships of the genus to the angiosperms and gymnosperms and also with Ephedre and Welwitschia are also fully discussed. The book is well illustrated by distribution maps for the species. as well as by line drawings and photographs, all of which are of excellent quality and well reproduced. many of these illustrations being original. There are a comprehensive bibliography and a single index to authors, plant names and subjects.

The book, which is well printed and reasonably well bound, can be recommended to research workers, teachers and students who will no doubt welcome this modern treatment of a topic that has been of interest for many years. Readers will find, however, that the authors are cautious in drawing phylogenetic conclusions, for the text ends with these words: "Thus Gnetum remains largely a phylogenetic puzzle. It is gymnospermous, but possesses some strong angiospermic features".

C. R. Metcalfe

\section{WORLD FOOD PROBLEMS}

World Review of Nutrition and Dietetics

Vol. 2. Edited by Geoffrey H. Bourne, assisted by Eileen M. H. Wilson. Pp. viii $+245+14$ plates. (London: Pitman Medical Publishing Co., Ltd., 1960.) 60s. net.

THE second volume in this series is slightly shorter than the first, but, as the editor remarks in the preface, it "spreads its international net even wider". There are two contributions from the United. States and one each from France, Sweden, South Africa, New Zealand, Switzerland and the United Kingdom. The subject-matter again covers a wide range, as the titles of the following four contributions out of a total of nine indicate: "Proteins and Hæmatopoiesis"; "The Effect of Malnutrition on the Eye, with Special Reference to Work with Experimental Animals"; "The Microbiology of Digestion"; "The Role of Carotene and Vitamin A in Animal Feeding". The reviews are written by wellinformed and experienced workers, who between them list some 2,000 references.

In the preface to Volume 1 the editor expressed the hope that each review would "provide a critical evaluation of the field" and added that "the author's interpretation, his views and his theorising will be welcomed as an integral part of his article". These aims have not been fully achieved. Some of the authors draw some conclusions from their extensive reviews; other confine themselves to a survey of the literature which ends abruptly without summary or comment. It would surely be useful if authors of multi-reference scientific reviews would attempt more often to summarize the salient points and briefly discuss the key question: Where do we go from here? This might help towards discarding litera. ture which has contributed at some stage to the advance of knowledge, but no longer needs to be consulted.

With this second volume, the World Review of Nutrition and Dietetics is fully launched and on the way to establishing itself as a publication of importance to research workers in nutrition and associated fields throughout the world. It is well printed and produced. The editor is to be congratulated on the high standard attained. $\quad$ W. R. AYKROYD 